\title{
COMMENT
}

\section{Is civil disobedience appropriate in the case of climate policies?}

\author{
Konrad Ott* \\ Ernst Moritz Arndt University of Greifswald, Institute for Botany and Landscape Ecology, Professorate Environmental Ethics, \\ Grimmer Strasse 88, 17487 Greifswald, Germany
}

\section{CONCEPT}

In their article, Lemons \& Brown (2011, this issue) take non-violent civil disobedience (NVCD) into account as a possible course of action that could and should raise public attention in the USA to the issue of climate change and to the repugnant role which the USA plays in international climate policy making. This comment does not address details of Lemons' \& Brown's (2011) provocative article but tries to explore from a continental perspective whether such a course of action can be justified on both moral and political grounds. According to the most common definition, NVCD is public protest which is strictly non-violent, morally driven, and directed against a state's policy making. NVCD is motivated by a deep moral concern of the policies of one's own nation. Since NVCD implies the intentional and purposive breaking of laws established by democratic authorities, NVCD stands in need of moral justification. Following Gert's book on 'Moral rules' (Gert 1966), many ethicists would like to adopt a prima facie moral obligation to act in accordance with laws. This obligation shifts the onus probandi to those who are willing to perform NVCD. This onus should be modest insofar as the basic political institutions are neither questioned nor challenged by NVCD. This onus can be addressed by casuistic reasoning, as Kant (1797) did in his 'Metaphysik der Sitten' ('Metaphysics of morals').

Systematically, NVCD actions have aspects of both heroic moral activity and illegal, somewhat criminal behavior. People involved in NVCD always take a personal risk when performing a course of action that implies law breaking. This risk is twofold, as these people often take some risks to their individual health if they climb smokestacks or disturb the killing of whales, and they may be punished in court for hav- ing broken laws; the legal system cannot simply ignore law breaking. There is even a third risk that such persons will be shamed by their opponents as criminals; however, this risk must be taken as unavoidable.

\section{TYPE OF SITUATION}

Imagine now a situation in which a minority recognizes (or believes that there are reasons to believe) that one's own nation fails morally on one important topic in the broad field of foreign affairs. That is to say that, in the perspective of this minority, one's own nation causes severe injuries and harm to many people living abroad. Such a situation may occur. The fact that democratic states do not fight wars against other democratic states does not imply that democratic states may never impose injuries upon foreign people by means of environmental externalities, economic regimes, or unequal exchange. Even democratic states may victimize other people by foreign policies. The minority is convinced that such victimization occurs.

First of all, the minority tries its very best to inform civil society about this moral failure. In doing so, its members have to recognize how deeply distorted and flawed the political communication about this issue really is. They have to realize that economic pressure groups produce counter-information in the name of sound scientific skepticism. Moreover, the system of mass-media communication is highly supportive of mass ignorance on this topic. Patterns of communication have been strongly distorted by those who profit from business as usual. After some time, the political sentiments of this minority turn toward a mixture of disappointment, anger, desperation, and shame. Studying the operations of the distorted mass-media system they 
find that spectacular activities are more likely to attract widespread attention in such a system. Thus, single groups among members of this minority decide to take some NVCD actions. Given this type of situation, we are entitled to ask, first, whether such activities are obligatory, honorable, permissible or false from the moral point of view and, second, how a legal culture in a democratic state should react to such activities.

\section{TRADITIONS}

I take it for granted that NVCD activities are strictly non-violent and respect the basic rights of the opponents involved. They are restricted to some minor period of time and even leave private property intact. If so, NVCD activities are more or less symbolic actions aimed at disturbing some routines of some agents who are in some sense to be blamed for the morally-repugnant policy making in foreign affairs that the minority wishes to be changed.

Historically, we honor some past NVCD activities. The invention of NVCD by Thoreau was caused by a marginal event of tax payment and Emerson ended this first instance of NVCD by his willingness to pay. Besides this humble origin, we honor Mohandas Karamchand Gandhi and Martin Luther King and their mass movements for the more heroic and, finally, successful political campaigns which involved NVCD activities. Moreover, we should remember the 'Go ins' in Ann Arbor in 1965 as students entered a military office to protest against the US warfare in Vietnam. I also remember some NVCD activities as performed by First Nations in the modern era of colonization, as described by Jeanette Armstrong in her 'Whispering in shadows' (Armstrong 2004, p. 112-121).

Given such instances and paradigm cases, we may only infer that not all NVCD activities are to be discredited. Current NVCD cannot simply be called legitimate because there were such honorable NVCD activities in the past. Current NVCD activities have to rely on arguments which are specific to the issue they refer to in order to gain their legitimacy. These arguments are reasons to presume that current NVCD activities are part of the morally honorable tradition of NVCD.

\section{PRAGMATISM AND NVCD}

NVCD may well be both permissible and honorable. Why? Assume that the minority group is right; then, it would be false to omit NVCD since one should not silence an issue of great moral significance. NVCD is directed against silencing topics of moral significance. Assume now that you as a bystander either (1) have ignored the topic at stake and you have not made up your mind yet or (2) you believe that the issue at stake is important indeed, but it has not been settled yet on scientific and moral grounds. In both cases, NVCD will prove to be provocative, troublesome and confusing to the moral mindsets of bystanders. They may and should ask themselves: Why are these people doing such things? Are they mere fanatics? Why are they taking such risks? Are they simply stupid idiots? Whose perspective is flawed on the matter? Seen from the pragmatic tradition in US philosophy such troubling should be welcomed from within this tradition. Pragmatic thinking always has endorsed puzzles and provocations. NVCD may be a starting point of abductive reasoning for neutral bystanders: There is a provocative and troubling kind of action being performed by other citizens. If the reasons for such action are sound and convincing, the provocative behavior must be understood as perfectly reasonable. Thus, it is imperative to reflect upon these reasons. The point I wish to make is that one should welcome NVCD in the spirit of Dewey, Mead, and Peirce.

\section{SUBSTANTIAL AGREEMENT}

In content and in substance, Lemons \& Brown (2011) give a correct general diagnosis of US climate policies. Having followed international climate change policy making since the Rio Summit in 1992, it seems hard to deny the repugnant role of the USA. For almost $20 \mathrm{yr}$, the USA has deeply failed morally over the issue of global climate change and policy making. This topic of global climate change is not a minor one but of paramount importance for future life prospects on planet Earth. Since climate change is not to be expected in some remote future but is already victimizing many people, especially poor people in the Global South, US climate policies are to be regarded as an indirect, but systematic injury against the basic rights of foreign people. Lemons' \& Brown's (2011) moral concerns are based on the 'White paper on the ethical dimensions of climate change' (Brown et al. 2005). Many other contributions to climate ethics and policy making (Ott 2010) can be added to assess and judge the role of the USA within the UNFCCC from the Rio Summit in 1992 to the recent summits in Bali, Copenhagen and Cancún.

From my European perspective and with respect to climate change policies only, the USA has continued over years to be the greatest rogue state on Earth. With deep regret, I also agree with Lemons \& Brown (2011) that the public sphere of reasoning has shifted towards a distorted and manipulative regime of 'brain washing' in the USA in recent years (see also Kearns 2007). Mass-media communication has been supportive of the 
false opinion that there are large and pervasive uncertainties at the very basics of climate science. All strategies for stronger mitigation policies have been blocked over years by coalitions of industries and governmental agencies. The emissions of green house gases (GHG) by the USA have increased by almost $20 \%$ since the Rio Summit. The USA has blocked all efforts to institutionalize a strong international climate regime. There has been a well organized and well financed campaign against persons and institutions that try to inform about the best-available scientific evidence on climate change. Single mistakes of the Intergovernmental Panel on Climate Change (IPCC), which have been corrected by the IPCC immediately, are exaggerated in order to cast general doubts on IPCC reports. With respect to its energy supply, the USA behaves like an addicted person searching for new stuff for the oil- and coal-sucking industries and consumerism.

This behavior had often been warranted by economic models which were designed to demonstrate that mitigation policies will not be efficient. If the net present value should be maximized, and if the rate of discount is set high, and if the rate of elasticity of substitution between climatic conditions and technologies is set close to 1 , and if the marginal rate of additional consumption values is set high, any conventional cost-benefit analysis will oppose short-term mitigation. Mainstream US economics has taken a huge burden of guilt in modeling global climate change in such ways. Since skepticism of anthropogenic climate change has lost scientific credit almost completely, new proposals of how to cope with climate change by means of solar radiation management (dimming sunlight by injection of sulfur particles into the stratosphere) have become widespread in the USA. A rapid shift from climate skepticism toward geo-engineering enthusiasm can be observed in many think tanks. It is fair to say that the Obama administration has taken some steps toward more ambitious mitigation policies and that many states and municipalities have been engaged in this respect (see Mehling 2009). However, it is also fair to say that the recent elections may create new barriers and obstacles to such policies. US climate change policies are at best unstable and will be replaced by new gridlocks at worst. In such a situation, a case in favor of NVCD can be made on, say, climate ethical grounds. Details, tactics, and risk-assessment of such NVCD are beyond my continental horizon. Strictly defined non-violence clearly does not disapprove creative fantasy of how to style and perform NVCD protest. NVCD can enclose motives stemming from theatre, artistic performance, dance, music, festivals, and the like. There should be a peaceful aesthetic of resistance.

One should perceive not only high-emission facilities but also the more ideological organizations as possible targets for NVCD. As has been said rightly, NVCD activists should not only climb smokestacks and harass fish trawlers but should also perform 'Go and Sit Ins' at some economics departments (Chicago and elsewhere). Analogically, NVCD could address think tanks and TV and broadcasting studios.

\section{SOLIDARITY}

Such NVCD deserves solidarity from abroad. Sharing the assumptions of Lemons \& Brown (2011), nongovernmental organisations (NGOs) should form a transatlantic alliance on NVCD actions and closely related activities. As citizens of the European Union (EU), we have to strongly and continually pressurize EU politicians to intensify the EUs role as a forerunner in mitigation activities. Given the new data on renewable energies, the EU can and should offer more than just a $20 \%$ reduction of GHG by 2020 compared to a 1990 baseline. A more ambitious $30 \%$ reduction target seems feasible. However, even the persons that favor strong mitigation on a global scale cannot deny that forerunner roles finally must be replaced by common action on a global scale. The EU will run into trouble if it offers an EU-wide GHG reduction target of $30 \%$ until 2020 if the USA refuses to make any binding obligations. Even if one has a critical eye on Russia and China (as I do), the USA is still the greatest hurdle toward global mitigation of climate change. As I fear, the USA feels highly comfortable in the Catch-22-situation by which China and the USA block each other.

What could solidarity look like? As consumers, EU citizens should not only reduce their personal carbon footprints but they should also avoid purchasing US products. EU citizens should use their purchasing power as a weapon against US politics. If it is fair to argue that the USA supports and subsidizes its industries by non-compliance to the Kyoto Protocol and by refusing to join a binding post-Kyoto regime, climatesensitive citizens can and should blame and shame US industries in the role of critical consumers. That is to say, that EU citizens should start long-term consumer boycott initiatives against US products if it was unequivocal that the industries involved have failed to comply with the global consensus to significantly reduce GHG emissions. Such a boycott would not reduce the quality of life of the average EU citizen substantially since most US products can be substituted by other commodities very easily. We would miss hardly anything. Such consumer boycott does not face the severe problems of trade measures (as border tax adjustment) under the (US-dominated) World Trade Organisation (WTO) regime. After the COP/MOP conference at Cancún, I think EU citizens should consider such a consumer boycott seriously. 


\section{A GERMAN REMINDER}

The final problem will be how the legal system of the USA will, and should, react to NVCD activities. Let me end my comment by pointing to a critical period in Germany's post-war history which I experienced as a young man. In Germany, we had a furious debate on NVCD and even on resistance in the 1970s and early 1980s as nuclear power plants and new nuclear missiles were provoking mass protests. For instance, almost 100000 people marched through a region called Wilstermarsch toward a site which had been reserved for a new nuclear power plant, although the demonstration had been forbidden by court. In another instance, people occupied a forested site close to Frankfurt where trees were to be felled to enlarge Frankfurt's airport ('Startbahn West'). This camp was supported by many locals often joining the camp. The camp was illegal with respect to property rights on land. In a further example of mass protest, roads were blocked when the US army transported Pershing missiles to Western Germany. According to German law, blocking roads is clearly illegal.

In those days, intellectuals, lawyers and philosophers debated how the legal system of Germany should react to such NVCD activities. Should, as some conservatives argued, the laws be applied rigidly to discourage NVCD activities by sentencing activists as harshly as possible? Or should a democratic system better tolerate such a protest by removing protesters from sites and roads using the police but not always prosecute NVCD actions in court? Would not a more de-escalating strategy be more promising with respect to political culture in general?

In the important volume on 'Ziviler Ungehorsam im Rechtsstaat' ('Civil disobedience in the state under the rule of law') edited by Peter Glotz there was a contribution by Jürgen Habermas 'Ziviler Ungehorsam - Testfall für den demokratischen Rechtsstaat' (Habermas 1983). Habermas argued that a democratic culture should not condemn such NVCD activities. Pointing to the US tradi-

Editorial responsibility: Darryl Macer,

Bangkok, Thailand tion of NVCD, Habermas argued that NVCD should be perceived as an intrinsic component of a self-confident democratic culture. Habermas warned against criminalizing people by ways of, as Habermas dubs it, authoritarian legalism.

If there are NVCD activities to come in the USA, the way the legal system reacts to them will cast some light on the overall political culture as it is presently in the USA. In principle, the system of juries might be supportive of NVCD since peer citizens have to judge NVCD activities. It will also be interesting to register which political camps may try to condemn and criminalize NVCD activism. We will pay much political attention to how such NVCD may be perceived in the USA.

\section{LITERATURE CITED}

Armstrong J (2004) Whispering in shadows. Theytus, Penticton

Brown D, Nancy T, Averill M, Baer P and others (2005) White paper on the ethical dimension of climate change. Rock Ethics Institute, University Park, PA. Available at http:// rockethics.psu.edu/climate/whitepaper/edcc-whitepaper. pdf

Gert B (1966) The moral rules. Harper \& Row, New York, NY

Habermas J (1983) Ziviler Ungehorsam-Testfall für den demokratischen Rechtsstaat. In: Glotz P (ed) (1983) Ziviler Ungehorsam im Rechtsstaat. Suhrkamp, Frankfurt/M, p 29-53

Kant I (1797) Metaphysik der Sitten. In: Weischedel W (1977) Werkausgabe, Vol 8. Suhrkamp, Frankfurt/M, p 303-634

Kearns L (2007) Cooking the truth: faith, science, the market and global warming. In: Kearns L, Keller C (eds) Ecospirit-religions and philosophies for the earth. Fordham University Press, New York, NY, p 97-124

Lemons J, Brown DA (2011) Global climate change and nonviolent civil disobedience. Ethics Sci Environ Polit 11:3-12

Mehling MA (2009) From gridlock to reengagement: US climate policy on the road to Copenhagen. In: Rodi M (ed) Bridging the divide in global climate policy: strategies for enhanced participation and integration. Lexxion, Berlin, p 107-124

Ott K (2010) Ethical foundations of climate change policies. In: Bergmann S, Gerten D (eds) Religion and dangerous environmental change. LIT, Münster, p 195-203

Submitted: 31 November 2010; Accepted: February 15, 2011 Proofs received from author(s): April 7, 2011 